\title{
Orf in Goats in China: Prevalence and Risk Factors
}

\author{
Yang Gao ${ }^{1}$, Yanqing Zhao ${ }^{2}$, Jianpeng Liu $^{3}$, Ming Zhou ${ }^{1}$, Heyuan Liu ${ }^{1}$, Fang Liu ${ }^{1}$, Wenyu Yang ${ }^{1}$ and Dekun Chen ${ }^{1}$ \\ 1. College of Veterinary Medicine, Northwest A\&F University, Yangling 712100, Shaanxi Province, China \\ 2. Department of Parasitology, College of Basic Medicine, Hubei University of Medicine, Shiyan 442000, Hubei Province, China \\ 3. Animal Diseases Control \& Prevention Centre of Yulin City, Yulin 719000, Shaanxi Province, China
}

\begin{abstract}
Orf is an important viral disease that affects goats and sheep and results in large economic losses. The aim of this study was to investigate the prevalence of orf and identify the potential risk factors of this disease in the main breeding areas of China. Among 1,241 blood samples collected from goats without clinical signs of orf, 433 samples (34.89\%) were positive for orf virus infection, which was detected by polymerase chain reaction (PCR) targeting a partial $B 2 L$ sequence of the viral genome. Moreover, a total of 874 buccal swab samples were collected, of which 64 samples (7.32\%) were positive for the orf virus on the basis of PCR detection. According to logistic regression, all of the variables, including age, breed, location and farm management, had significant impacts on the prevalence of orf. Lambs under intensive management in Yunnan province were more susceptible to orf virus infection than animals in other groups. Anglo-Nubian goats were at more risk of orf positivity than other breeds, whereas Saanen dairy goats were at significantly less risk. In summary, as the first epidemiological study of orf in China, this investigation suggested that orf is a neglected disease that requires more attention in the future.
\end{abstract}

Key words: Orf prevalence, risk factors, goats, China.

\section{Introduction}

Orf, also known as contagious pustular dermatitis, contagious ecthyma, sore mouth or scabby mouth, is an important viral disease with a worldwide distribution. Orf primarily affects sheep and goats and substantially decreases animal welfare, resulting in erythematous macules, papules, vesicles, pustules and scabs around the lips and nostrils [1,2]. Orf infection in kids and lambs results in more severe disease than in adult animals, because it impairs lambs' ability to suck and graze [3]. Up to $100 \%$ morbidity and $10 \%$ mortality from orf has been observed in lambs [4]. The annual economic losses from orf have been reported to be up to 10 million pounds based on 2.167 million sheep affected by orf; this estimate includes live weight loss, premature culling, treatment and control costs [2]. In addition, orf is a zoonotic disease. Orf has been reported in humans, presenting as papules and pustular lesions on the hands, fingers and

Corresponding author: Dekun Chen, Ph.D., research field: preventive veterinary medicine. faces of subjects who had direct or indirect contact with infected animals, such as dairy farm workers, veterinarians and religious slaughter participants [5]. Thus, more attention should be paid to this disease. However, information regarding the prevalence of orf in China is limited, and approximately 141.36 million goats and 143.68 million sheep are bred according to the China statistical yearbook [6].

Orf virus (ORFV), a member of the family Poxviridae genus Parapoxvirus, is the causal agent of orf [5]. The genome of ORFV is a $138-\mathrm{kbp}$ linear double-stranded DNA containing 132 putative genes [7]. Of these genes, the $B 2 L$ gene encodes the major envelope protein, which is $42 \mathrm{kDa}$, highly immunogenic and able to induce both antibody and cell-mediated responses [8]. Moreover, the FIL gene encodes a major heparin binding protein involved in virus binding to the cell in the early stages of infection; it is a possible subunit vaccine for ORFV $[9,10]$. The virus interferon resistant gene (VIR) encodes a double-stranded RNA binding protein that is expressed early and inhibits the antiviral activity 
induced by interferons [11]. All of these genes are highly conserved among ORFV isolates and have been used for the identification, molecular characterization and phylogenetic analysis of ORFV $[12,13]$.

In this study, the sensitivity of $B 2 L, F 1 L$ and VIR gene-based polymerase chain reaction (PCR) assays for ORFV detection was evaluated. Based on the PCR detection method, the prevalence of orf in goats in China was investigated by using conventional PCR targeting a partial $B 2 L$ sequence and also assessed the potential risk factors accounting for the high prevalence of orf.

\section{Materials and Methods}

\subsection{Animals and Sampling}

A total of 1,265 goats for meat and milk production were randomly selected from Shaanxi, Shandong and Yunnan provinces of China between May 2012 and October 2014 (Fig. 1 and Table 1). A total of 1,241 healthy goats without clinical signs were included in this study; an additional 24 animals with ORFV symptoms were included as controls (Fig. 2). Ethylenediamine tetraacetic acid (EDTA)-anticoagulated blood from all the animals along with 874 buccal swabs from the healthy goats were collected, transported to the laboratory and stored at $4{ }^{\circ} \mathrm{C}$. The swabs were suspended in $0.5 \mathrm{~mL}$ of sterile phosphate-buffered saline and incubated overnight at $4{ }^{\circ} \mathrm{C}$, followed by swirling. Then, the suspension was stored at $4{ }^{\circ} \mathrm{C}$ for DNA extraction.

\subsection{Isolation of Genomic DNA}

DNA extraction from whole blood was performed as previously described with modifications of the method in Ref. [14]. Briefly, whole blood was diluted at a 1:1 ratio with distilled water and then lysed with an equal volume of $6 \mathrm{M} \mathrm{NaI}$, followed by extraction with chloroform/isoamyl alcohol. After centrifugation, genomic DNA was precipitated with a 0.6 volume-to-volume ratio of isopropanol and washed with $70 \%$ ethanol. Then, the DNA pellet was dissolved in $20 \mu \mathrm{L}$ of Tris-EDTA buffer $(100 \mathrm{mM}$ Tris-HCl, $1 \mathrm{mM} \mathrm{Na}_{2}$ EDTA, pH 8). The quantity and

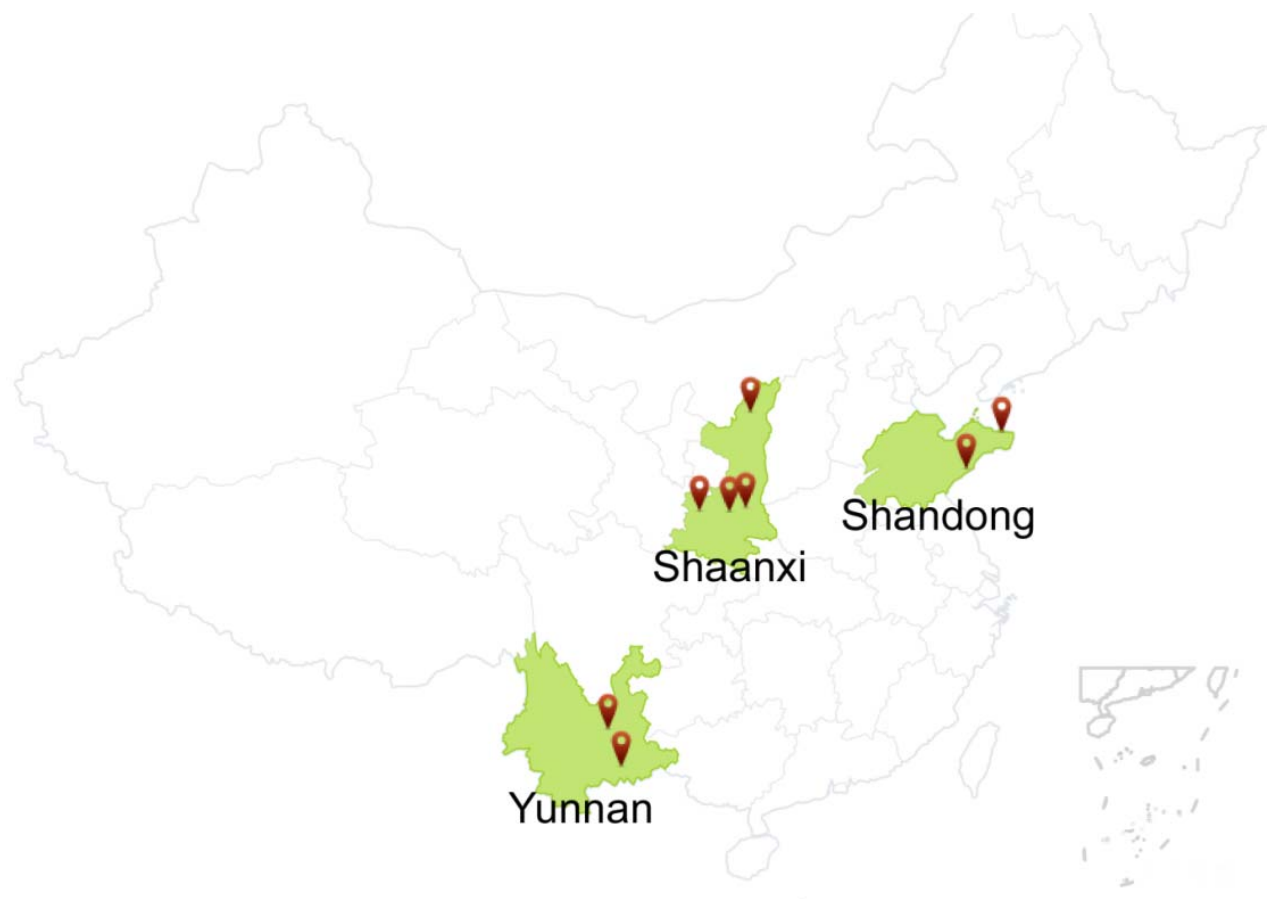

Fig. 1 Map of the main breeding areas of China involved in this investigation. 
Table 1 Association between selected risk factors and positivity of orf in blood samples of goat in China.

\begin{tabular}{|c|c|c|c|c|c|c|c|c|}
\hline \multirow{2}{*}{ Risk factors } & \multirow{2}{*}{ No. of samples } & \multirow{2}{*}{ No. and $\%$ of positive } & \multirow{2}{*}{$\beta$} & \multirow{2}{*}{ SE } & \multirow{2}{*}{$P$} & \multirow{2}{*}{$\operatorname{Exp}(\beta)$} & \multicolumn{2}{|c|}{$95.0 \%$ CI for $\operatorname{Exp}(\beta)$} \\
\hline & & & & & & & Lower & Upper \\
\hline \multicolumn{9}{|l|}{ Goat breeds } \\
\hline Anglo-Nubian goat & 48 & $31(64.58 \%)$ & -1.200 & 0.515 & 0.020 & 0.301 & 0.110 & 0.826 \\
\hline Guanzhong dairy goat & 344 & $117(34.01 \%)$ & -0.248 & 0.226 & 0.272 & 0.780 & 0.501 & 1.215 \\
\hline Laoshan dairy goat & 49 & $24(48.98 \%)$ & 0.256 & 0.349 & 0.464 & 1.291 & 0.651 & 2.560 \\
\hline Saanen dairy goat & 567 & $188(33.16 \%)$ & -0.709 & 0.223 & 0.001 & 0.492 & 0.318 & 0.762 \\
\hline Wendeng dairy goat & 19 & $14(73.68 \%)$ & 0.435 & 0.589 & 0.460 & 1.545 & 0.487 & 4.903 \\
\hline White cashmere goat & 214 & $59(27.57 \%)$ & - & - & - & - & - & - \\
\hline \multicolumn{9}{|l|}{ Location } \\
\hline Shaanxi & 1,060 & $320(30.19 \%)$ & - & - & - & - & - & - \\
\hline Shandong & 68 & $38(55.88 \%)$ & - & - & - & - & - & - \\
\hline Yunnan & 113 & $75(66.37 \%)$ & 1.813 & 0.329 & 0.000 & 6.127 & 3.218 & 11.667 \\
\hline \multicolumn{9}{|l|}{ Age (year) } \\
\hline$<1$ & 172 & $106(61.63 \%)$ & 1.009 & 0.205 & 0.000 & 2.743 & 1.837 & 4.096 \\
\hline$\geq 1$ & 1,069 & $327(30.59 \%)$ & - & - & - & - & - & - \\
\hline \multicolumn{9}{|l|}{ Management } \\
\hline Intensive farm & 1,109 & $407(36.70 \%)$ & 1.193 & 0.287 & 0.000 & 3.297 & 1.880 & 5.780 \\
\hline Extensive farm & 132 & $26(19.70 \%)$ & - & - & - & - & - & - \\
\hline Constant & - & - & -1.856 & 0.308 & 0.000 & 0.156 & - & - \\
\hline
\end{tabular}

CI: confidence interval; SE: standard error.

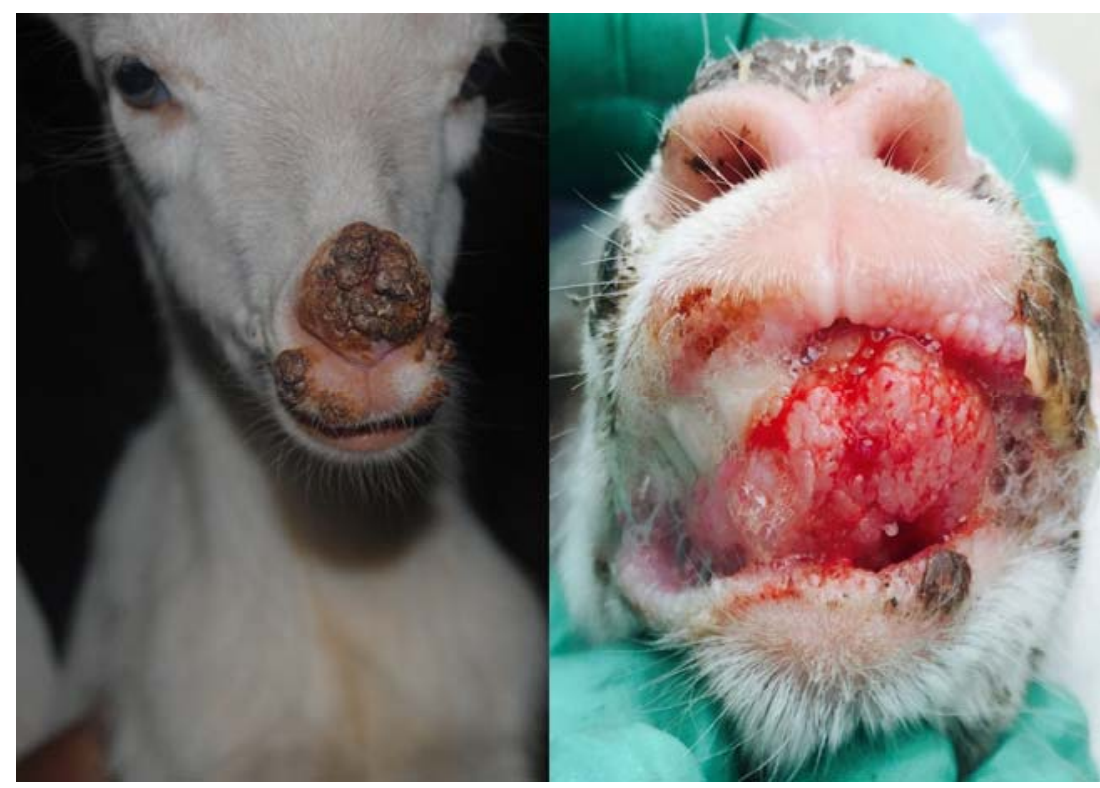

Fig. 2 Typical clinical symptoms of orf in goats.

quality of the DNA samples were assessed using a UV spectrophotometer (Q3000, Quawell, USA).

Viral DNA was extracted from buccal swabs from the goats as previously described in Ref. [15]. Briefly, the swab suspension was incubated in a lysis buffer containing $4 \mathrm{M}$ guanidinium thiocyanate acid for $10 \mathrm{~min}$ at room temperature, and the cold isopropyl alcohol was added to precipitate DNA. The mixture was centrifuged at $14,000 \times \mathrm{g}$ for $10 \mathrm{~min}$ at $4{ }^{\circ} \mathrm{C}$, and the DNA pellet was washed with $70 \%$ ethanol and dissolved in $10 \mu \mathrm{L}$ of Tris-EDTA buffer for use. The quantity and quality of the DNA samples were assessed as described above. 


\subsection{Development and Application of PCR}

Primers that amplify specific segments of the $B 2 L$, $F 1 L$ and VIR genes were described by Li et al. [16]. The components of the PCR reaction mixture were as follows: $2.5 \mu \mathrm{L} 10 \times$ PCR buffer, $25 \mathrm{ng}$ template DNA, $0.2 \mathrm{mM}$ dNTPs, $1.5 \mathrm{mM} \mathrm{MgCl}_{2}, 0.4 \mu \mathrm{M}$ of primer and $0.05 \mathrm{U} / \mu \mathrm{L}$ Taq polymerase (TaKaRa, Dalian, China). The PCR program had an initial denaturation at $94{ }^{\circ} \mathrm{C}$ for $5 \mathrm{~min}$, followed by 35 cycles consisting of $30 \mathrm{~s}$ at $94{ }^{\circ} \mathrm{C}, 30 \mathrm{~s}$ at $56{ }^{\circ} \mathrm{C}, 35 \mathrm{~s}$ at $72{ }^{\circ} \mathrm{C}$ and a final extension at $72{ }^{\circ} \mathrm{C}$ for $10 \mathrm{~min}$. The amplified PCR products were electrophoresed on $2 \%$ agarose gels and visualized with ethidium bromide staining. The purified PCR products were sequenced by GenScript Corp. (Nanjing, China), and the sequences for each gene were aligned with published data in databases to confirm the presence of ORFV. DNA isolated from ORFV-infected primary bovine testis cells was used as a positive control, and samples with goat DNA or without genomic DNA were included as negative controls. Other Parapoxvirus isolates, including Capripox virus and Sheeppox virus, were included in the PCR assay to assess the specificity of the designed primers. The sensitivity of the PCR was evaluated by using serial 10-fold dilutions of mock-infected primary bovine testis cells $\left(10^{5.2} \mathrm{TCID}_{50} / \mathrm{mL}\right)$, and the detection limit of the PCR reactions was defined as the highest fold dilution producing a detectable PCR product.

After optimization, DNA isolated from 1,265 blood samples and 874 buccal swab samples were analyzed by using the PCR assay based on a partial $B 2 L$ sequence.

\subsection{Statistics Analysis}

A binary logistic regression model was used, and a backwards-stepwise elimination procedure of variables was performed to identify significant risk factors contributing to the prevalence of orf in goats. These variables included age, breed, location and management. $P<0.05$ in the likelihood ratio test was considered to be statistically significant. All analyses were performed using SPSS for Windows (version 17.0, Chicago, IL, USA).

\section{Results}

In this study, a PCR assay was successfully established to amplify amplicons of 540, 437 and 264 bp for the $B 2 L, F 1 L$ and $V I R$ genes, respectively. As shown in Fig. 3a, the threshold sensitivity for each PCR was determined to be as high as $10^{5}$ fold dilution of mock-infected primary bovine testis cells $\left(10^{0.2} \mathrm{TCID}_{50} / \mathrm{mL}\right)$, at which the amplified product of
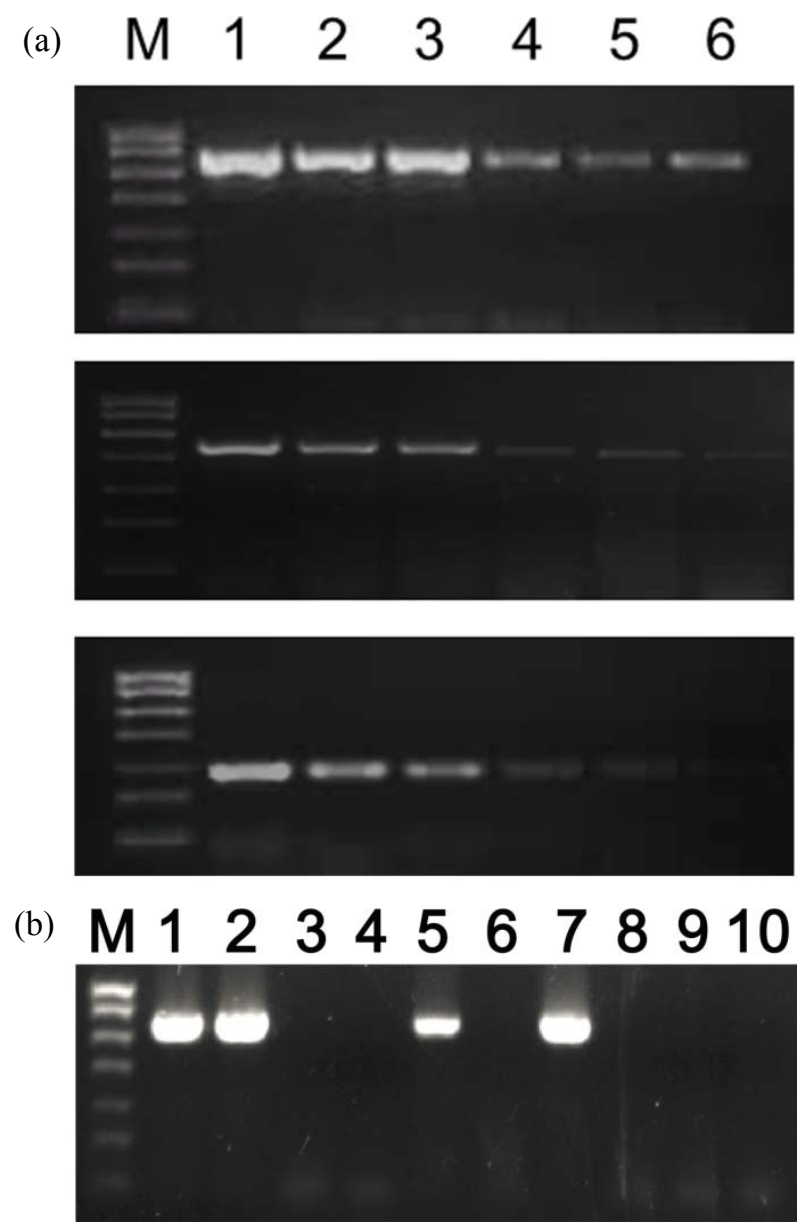

Fig. 3 The sensitivity of the PCR evaluated by using serial 10 -fold dilutions of mock-infected primary bovine testes cells $\left(10^{5.2}-10^{0.2} \mathrm{TCID}_{50} / \mathrm{mL}\right)$ (a) and the specificity of the PCR detected (b).

Lane M: 700-bp Trans DNA marker I; lane 1 and 2: positive control; lane 3-7: DNA from the collected blood samples; lane 8 and 9: DNA of other Parapoxvirus isolates including Capripox virus and Sheeppox virus; lane 10: negative control. 
$B 2 L$ was observed more clearly than that of the $F 1 L$ or $V I R$ gene. For this reason, the $B 2 L$ gene was selected for development of a reliable PCR assay for the diagnosis of ORFV infection. The specificity of PCR amplification of the $B 2 L$ gene-specific primers was confirmed by the absence of amplification of control DNA from other related Parapoxvirus (Fig. 3b).

Among the 24 blood samples collected from goats with clinical symptoms of orf, 23 samples were found to be positive for ORFV by using the optimized PCR targeting the $B 2 L$ gene. Of the 1,241 blood samples collected from goats without clinical symptoms of orf, 433 samples $(34.89 \%)$ were ORFV positive. The proportion of goats infected with ORFV was the highest among the Wendeng dairy goats $(73.68 \%)$ and the lowest among the White cashmere goats (27.57\%). The prevalence of orf varied among the investigated provinces, with the values in Shaanxi, Shandong and Yunnan of $30.19 \%, 55.88 \%$ and $66.37 \%$, respectively. In total, 172 and 1,069 goats fit the lamb and adult categories, respectively. The ORFV-positive rate in the lambs and adults was $61.63 \%$ (106) and $30.59 \%$ (327), respectively. The prevalence of orf on farms under intensive grazing management was $36.70 \%$, whereas this value was $19.70 \%$ on extensive organic farms. The descriptive epidemiology of orf in this study is provided in Table 1.

According to the logistic regression, all variable factors, including age, breed, location and farm management, had significant effects on the prevalence of orf. A final logistic regression model was constructed and fit the data well $\left(\chi^{2}=1.184, d f=4, P\right.$ $=0.881)$ according to Hosmer-Lemeshow goodness-of-fit. The presented incidence model showed that lambs $(\operatorname{Exp}(\beta)=2.743,95 \%$ confidence interval $(\mathrm{CI})=1.837-4.096, P=0.000)$ under intensive management conditions $(\operatorname{Exp}(\beta)=3.297,95 \%$ $\mathrm{CI}=1.880-5.780, P=0.000)$ in Yunnan province $(\operatorname{Exp}(\beta)=6.127,95 \% \mathrm{CI}=3.218-11.667, P=0.000)$ were more susceptible to ORFV infection than animals in other groups. Anglo-Nubian goats $(\operatorname{Exp}(\beta)=0.301$,
Table 2 The prevalence of orf in samples from ovine buccal swabs in China.

\begin{tabular}{lll}
\hline Location & No. of samples & No. and \% of positive \\
\hline Shaanxi & 661 & $61(9.23 \%)$ \\
Shandong & 67 & $1(1.49 \%)$ \\
Yunnan & 146 & $2(1.37 \%)$ \\
\hline Total & 874 & $64(7.32 \%)$ \\
\hline
\end{tabular}

$95 \% \mathrm{CI}=0.110-0.826, P=0.020)$ had a higher risk of ORFV infection than the other breeds in this study, whereas Saanen dairy goats $(\operatorname{Exp}(\beta)=0.492,95 \%$ CI $=0.318,0.762, \mathrm{P}=0.001)$ had lower risk.

In addition to blood samples, a total of 874 buccal swab samples were collected, out of which ORFV was detected in $64(7.32 \%)$ samples by using the PCR assay for the $B 2 L$ gene. The prevalence of orf was higher in Shaanxi province $(9.23 \%)$ compared with Shandong province $(1.49 \%)$ and Yunnan (1.37\%) province (Table 2).

\section{Discussion}

The overall prevalence of orf $(34.89 \%)$ in goats in this study was lower than the prevalence of $60 \%$ in Hubei province in China as diagnosed based on clinical symptoms [17]. Higher morbidity from orf (61\%) has been reported in the Central Himalayas $\left(29.48^{\circ} \mathrm{N}, 79.65^{\circ} \mathrm{E}\right)$ [18]. However, the prevalence detected in the current study was higher than that in England, which has been calculated as $1.88 \%$ for ewes and $19.51 \%$ for lambs [19].

The occurrence of orf was influenced by multiple factors in logistic regression analysis in the present study, including age, breed, location of the farm and management. Consistently with results from previous studies, lambs, especially suckling lambs and lambs after weaning, are more susceptible to ORFV than ewes $[5,20]$. This difference might be explained by the incomplete immunity and presence of orphan lambs. The immunity of lambs is incomplete, mainly due to their immature immune system and imperfect immunity. Passive immunity to ORFV mediated by antibodies via colostrum from vaccinated ewes is considered to be a possible solution, but no protective 
effect has been observed in lambs receiving passive immune protection, as demonstrated by challenge with ORFV, which still caused disease [21, 22]. In the intensive farms of this study, most of the lambs were isolated from ewes and hence were orphaned. More importantly, these orphan lambs were flocked and bred together, and the ORFV-infected lambs, which could have contaminated their environment and caused new infections, were rarely separated from the healthy animals. Hence, high morbidity was observed not only in lambs but also in adults.

Goats are generally more susceptible and develop more severe cases of orf than sheep [5, 23]. Boer goats and crosses are more susceptible to ORFV infection and develop severe disease according to existing reports [24]. In this study, Anglo-Nubian goats were more susceptible to orf, whereas Saanen dairy goats appeared to be more resistant to ORFV infection. The inconsistency between the present and previous studies might be due to the limited sample size in this study, particularly for Wendeng dairy goats, Laoshan dairy goats and Anglo-Nubian goats. More samples collected from each goat breed should be included in the future to confirm this phenomenon.

In this study, morbidity from orf was increased in intensive management compared with extensive farm management. Notably, Hosie [20] has suggested that major outbreaks of orf are generally associated with intensive farming systems. In intensive management of goats in China, goats are usually restricted to small pens with high density, which results in reduced activity. This intensive management would not benefit goats regarding improving their immunity. Instead, this management causes a favorable environment for the spread of viruses. In addition, the degree of weed infestation should be considered [19]. Goats maintained under an intensive management system are typically fed with forage crops and maize silage, which might cause wounding around the mouth, whereas extensive conditions offer good grassland for goats to graze. Although the intensive management of goats has shortcomings, more intensive management could be a favorable option for sustainable development policy under the high population pressure.

The farms with the highest orf morbidity in this study were located in Yunnan province, Southwestern China $\left(22^{\circ}-28^{\circ} \mathrm{N}, 97^{\circ}-105^{\circ} \mathrm{E}\right)$. Yunnan province, particularly Kunming city, is characterized by a comfortable spring-like climate year round. ORFV is likely to survive for several months in such an environment, because extreme temperature and UV light can inactivate this virus [23]. To further investigate this issue, the physico-chemical properties of Parapoxvirus should be more thoroughly studied and updated, and more samples should be collected from Yunnan province, Shandong province, as well as the entire country.

The results in this study indicate that the prevalence of ORFV infection was considerably increased when detected based on the blood positive rate for virus rather than swab samples. This finding suggests that the prevalence of orf may be underestimated, because no clinical symptoms have been observed in subclinically infected animals. Subclinical ORFV infection indeed occurs, because ORFV can transmit from clinically normal ewes to susceptible sheep and may serve as a source for new outbreaks, because fatal orf in lambs following long distance transportation has been reported [4, 25]. However, a relatively low positive rate in swabs could be explained by the fact that ORFV is not detectable $30 \mathrm{~d}$ after challenge in either newly regenerated epidermis or the remnants of surface scabs, although it is present in scabs overlying healing lesions by day 20 [1].

\section{Conclusions}

The prevalence of orf in goats in China was high. And there were many risk factors that influenced the prevalence of orf, including age and breed of animals, feeding, location and management of the farm. Orf is a neglected disease in China, particularly in the main 
breeding areas, and is underestimated by both farmers and veterinarians. This investigation adds a new dimension to the significance of the disease.

\section{Acknowledgments}

The authors thank Dr. Yuchen Nan from Northwest A\&F University, Yangling, China for the improvement of this manuscript. This study was supported by the Science and Technology Co-ordinate Innovation Project of Shaanxi Province, China (Grant No. 2015KTTSNY04-04 and Grant No. 2013KTZB02-02-03).

\section{References}

[1] McKeever, D. J., Jenkinson, D. M., Hutchison, G., and Reid, H. W. 1988. "Studies of the Pathogenesis of Orf Virus Infection in Sheep." Journal of Comparative Pathology 99 (3): 317-28.

[2] Bennett, R., and Ijpelaar, J. 2005. "Updated Estimates of the Costs Associated with Thirty Four Endemic Livestock Diseases in Great Britain: A Note.” J. Agr. Econ. 56 (1): 135-44.

[3] Martins, M., Cargnelutti, J. F., Weiblen, R., and Flores, E. F. 2014. "Pathogenesis in Lambs and Sequence Analysis of Putative Virulence Genes of Brazilian Orf Virus Isolates." Vet. Microbiol. 174 (1-2): 69-77.

[4] Gumbrell, R. C., and McGregor, D. A. 1997. "Outbreak of Severe Fatal Orf in Lambs." Vet. Record 141 (6): 150-1.

[5] Scagliarini, A., Piovesana, S., Turrini, F., Savini, F., Sithole, F., and McCrindle, C. M. 2012. "Orf in South Africa: Endemic but Neglected." Onderstepoort J. Vet. Res. 79 (1): 1-8.

[6] National Bureau of Statistics of the Peoples' Republic of Chnia. 2013. China Statistical Yearbook.

[7] Mercer, A. A., Ueda, N., Friederichs, S. M., Hofmann, K., Fraser, K. M., Bateman, T., and Fleming, S. B. 2006. "Comparative Analysis of Genome Sequences of Three Isolates of Orf Virus Reveals Unexpected Sequence Variation." Virus Res. 116 (1-2): 146-58.

[8] Sullivan, J. T., Mercer, A. A., Fleming, S. B., and Robinson, A. J. $1994 . \quad$ "Identification and Characterization of an Orf Virus Homologue of the Vaccinia Virus Gene Encoding the Major Envelope Antigen p37K." Virology 202 (2): 968-73.

[9] Gallina, L., Scagliarini, A., Ciulli, S., and Prosperi, S. 2004. "Cloning and Expression of the Orf Virus F1L Gene: Possible Use as a Subunit Vaccine." Vet. Res. Commun. 28: 291-3.
[10] Scagliarini, A., Gallina, L., Dal Pozzo, F., Battilani, M., Ciulli, S., and Prosperi, S. 2004. "Heparin Binding Activity of Orf Virus F1L Protein.” Virus Res. 105 (2): 107-12.

[11] Haig, D. M., McInnes, C. J., Thomson, J., Wood, A., Bunyan, K., and Mercer, A. 1998. "The Orf Virus OV20.0L Gene Product Is Involved in Interferon Resistance and Inhibits an Interferon-Inducible, Double-Stranded RNA-Dependent Kinase.” Immunology 93 (3): 335-40.

[12] Zhao, K., Song, D., He, W., Lu, H., Zhang, B., Li, C., Chen, K., and Gao, F. 2010. "Identification and Phylogenetic Analysis of an Orf Virus Isolated from an Outbreak in Sheep in the Jilin Province of China." Vet. Microbiology 142 (3-4): 408-15.

[13] Abrahao, J. S., Borges, I. A., Mazur, C., Lobato, Z. I., Ferreira, P. C., Bonjardim, C. A., Trindade, G. S., and Kroon, E. G. 2012. "Looking Back: A Genetic Retrospective Study of Brazilian Orf Virus Isolates." Vet. Record 171 (19): 476.

[14] Loparev, V. N., Cartas, M. A., Monken, C. E., Velpandi, A., and Srinivasan, A. 1991. "An Efficient and Simple Method of DNA Extraction from Whole Blood and Cell Lines to Identify Infectious Agents.” J. Virol. Methods 34 (1): 105-12.

[15] Casas, I., Powell, L., Klapper, P. E., and Cleator, G. M. 1995. "New Method for the Extraction of Viral-RNA and DNA from Cerebrospinal-Fluid for Use in the Polymerase Chain-Reaction Assay." J. Virol. Methods 53 (1): 25-36.

[16] Li, Q. R., Li, J., Tian, T. T., Yao, Y. L., Xu, J. Y., and Chen, D. K. 2013. "Development of Multiplex PCR for Detecting Orf Virus." Progress in Veterinary Medicine 34: 36-8.

[17] Zhang, K. S., Lu, Z. X., Shang, Y. J., Zheng, H. X., Jin, Y., He, J. J., and Liu, X. T. 2010. "Diagnosis and Phylogenetic Analysis of Orf Virus from Goats in China: A Case Report." Virology Journal 7: 78.

[18] Mondal, B., Bera, A. K., Hosamani, M., Tembhurne, P. A., and Bandyopadhyay, S. K. 2006. "Detection of Orf Virus from an Outbreak in Goats and Its Genetic Relation with Other Parapoxviruses." Vet. Res. Commun. 30 (5): 531-9.

[19] Onyango, J., Mata, F., McCormick, W., and Chapman, S. 2014. "Prevalence, Risk Factors and Vaccination Efficacy of Contagious Ovine Ecthyma (Orf) in England." Vet. Record 175 (13): 326.

[20] Hosie, B. 2012. "Orf: Reasons to Take an Interest in Control." Vet. Record 170: 671-2.

[21] Buddle, B. M., and Pulford, H. D. 1984. "Effect of Passively-Acquired Antibodies and Vaccination on the Immune Response to Contagious Ecthyma Virus." Vet. 
Microbiology 9 (6): 515-22.

[22] Mercer, A. A., Yirrell, D. L., Reid, H. W., and Robinson, A. J. 1994. "Lack of Cross-Protection between Vaccinia Virus and Orf Virus in Hysterectomy-Procured, Barrier-Maintained Lambs." Vet. Microbiology 41 (4): 373-82.

[23] Nandi, S., De, U. K., and Chowdhury, S. 2011. "Current Status of Contagious Ecthyma or Orf Disease in Goat and Sheep: A Global Perspective." Small Ruminant Res. 96
(2-3): 73-82.

[24] De la Concha-Bermejillo, A., Guo, J., Zhang, Z., and Waldron, D. 2003. "Severe Persistent Orf in Young Goats." Journal of Veterinary Diagnostic Investigation 15 (5): 423-31.

[25] Nettleton, P. F., Gilray, J. A., Yirrell, D. L., Scott, G. R., and Reid, H. W. 1996. "Natural Transmission of Orf Virus from Clinically Normal Ewes to Orf-Naive Sheep." Vet. Record 139: 364-6. 